\title{
Catching the reversible formation and reactivity of surface defective sites in MOFs: an operando
}

\section{Ambient Pressure-NEXAFS investigation}

Luca Braglia ${ }^{\dagger *}$, Francesco Tavani ${ }^{\ddagger}$, Silvia Mauri ${ }^{\dagger}$, Raju Edla ${ }^{\dagger}$, , Damjan Krizmancic ${ }^{\dagger}$, Alessandro Tofoni $i^{\ddagger}$,Valentina Colombo", Paola D'Angelo ${ }^{+}$, Piero Torelli ${ }^{\dagger}$

AUTHOR ADDRESS

${ }^{\dagger}$ CNR- Istituto Officina dei Materiali, TASC, Trieste, Italy

* Dipartimento di Chimica, Università di Roma "La Sapienza", P.le A. Moro 5, 00185 Roma, Italy

$\S$ Institute for Photon Science and Synchrotron Radiation, Karlsruhe Institute of Technology, Eggenstein-Leopoldshafen, Germany

"Dipartimento di Chimica, Università degli Studi di Milano, Via Golgi 19, 20133 Milan, Italy

\section{Corresponding Author}

*braglia@iom.cnr.it 
ABSTRACT In this work, we apply for the first time ambient pressure operando soft X-ray Absorption Spectroscopy to investigate the location, structural properties and reactivity of the defective sites present in the prototypical metal organic framework HKUST-1. We obtain direct evidence that $\mathrm{Cu}^{+}$defective sites form upon temperature treatment of the powdered form of HKUST-1 at $160{ }^{\circ} \mathrm{C}$ and that they are largely distributed on the material surface. Further a thorough structural characterization of the $\mathrm{Cu}^{+} / \mathrm{Cu}^{2+}$ dimeric complexes arising from the temperature induced dehydration/decarboxylation of the pristine $\mathrm{Cu}^{2+} / \mathrm{Cu}^{2+}$ paddlewheel units is reported. In addition to characterization of the surface defects, we demonstrate that $\mathrm{CO}_{2}$ may be reversibly adsorbed and desorbed from the surface defective $\mathrm{Cu}^{+} / \mathrm{Cu}^{2+}$ sites. These findings show that ambient pressure soft-XAS, combined with state-of-the-art theoretical calculations, allowed us to shed light into the mechanism involving the decarboxylation of the paddlewheel units at the surface to yield $\mathrm{Cu}^{+} / \mathrm{Cu}^{2+}$ complexes and their reversible restoration upon exposure to gaseous $\mathrm{CO}_{2}$

\section{TOC GRAPHICS}

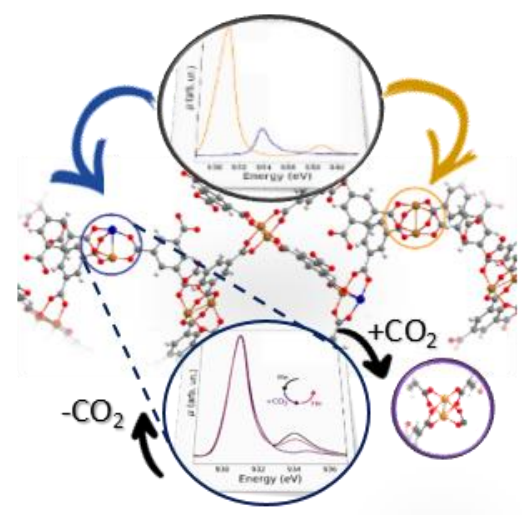

KEYWORDS HKUST-1, Ambient pressure NEXAFS, Defects in MOFs, soft-XAS, $\mathrm{CO}_{2}$ abatement. 
Metal organic frameworks (MOFs) are emerging nanoporous materials obtained from the binding of polydentate organic molecules (the linkers) to metal ions or clusters (the nodes) generating three-dimensional structures featuring pores with nanosized apertures and ultra-high internal surface areas (up to $10.000 \mathrm{~m}^{2} \mathrm{~g}^{-1}$ ). ${ }^{1}$ Tailor-made MOFs for specific applications, such as highly selective adsorbents for target molecules, can be obtained by engineering the coordination of the linkers to the metal nodes. ${ }^{2}$ The combination of compositional modularity, synthetic ease and multifunctional properties have led to the introduction of MOFs into a wide range of application fields, such as gas sorption (separation and storage) ${ }^{3,4,5,6,7,8}$, catalysis, ${ }^{9,10,3}$ photocatalysis, ${ }^{11}$ sensing, ${ }^{12}$ heat transformation ${ }^{13}$ and drug delivery ${ }^{14,15}$. Within these applications, MOFs have arisen as promising materials for the selective and reversible capture of $\mathrm{CO}_{2}{ }^{16,17,18}$ a crucial environmental issue, and the introduction of coordinatively active sites (CUSs), and their postsynthetic functionalization have been found to be very powerful approaches to improve $\mathrm{CO}_{2}$ uptake. ${ }^{19,20,21}$ CUSs are thus homogeneously dispersed within the framework and available as defined, isolated, single active sites for gas adsorption and catalysis, with an unprecedented mimicking of enzyme behavior. ${ }^{3}$ However, it is still unclear whether the MOF catalytic and absorption properties are only related to the CUSs present in the 'perfect' crystal structure or are enhanced, or even due, to the presence of structural defects within the MOF itself. In this context, an archetypal example, widely studied for both its activity at the $\mathrm{Cu}$-open metal sites and the defect-engineering of its crystal structure, is the well-known HKUST-1 (denoted also as $\mathrm{Cu}_{3}(\mathrm{BTC})_{2}, \mathrm{BTC}=$ benzene-1,3,5-tricarboxilate, Figure S1). ${ }^{22}$

However, despite the long history of research on the causes and nature of the mixed valence defective dimer sites in HKUST-1 (brief summary is reported in the supporting information), full agreement on their formation, structure and reactivity has not yet been reached. 
While hard X-ray spectroscopy (XAS) at the Cu K-edge has been widely employed to characterize the local structure and reactivity of the HKUST-1 copper sites, ${ }^{23-25,26}$ the application of soft X-ray spectroscopy at the $\mathrm{Cu} \mathrm{L}_{2,3}$-edges has been severely limited by the need of high vacuum conditions and tailored experimental set-ups. In a very recent development, specific cells have been designed that allow soft-XAS experiments to be carried out at atmospheric pressure under operando conditions (AP-NEXAFS) (techniques details are in the supporting information). In this case softXAS is operated in total electron yield (TEY) detection mode which renders the technique surface sensitive, owing to the low electron escape depth which limits the thickness of the probed sample to a few atomic layers below the surface. The newly developed AP-NEXAFS technique is a powerful method to unveil the nature of CUSs in MOFs during adsorption experiments or even catalytic reactions, since its surface sensitivity $(<10 \mathrm{~nm})$ is a crucial feature to thoroughly characterize the defective sites that occur at the surface of the investigated material.

Figure 1a shows the comparison between the $\mathrm{Cu}_{2}$-edge XAS spectrum of the pristine HKUST1 collected in He flux $(50 \mathrm{ml} / \mathrm{min}, 1 \mathrm{bar})$ at $\mathrm{RT}$ and that of the same sample exposed to a He flux at $160^{\circ} \mathrm{C}$ for 10 minutes. The spectrum collected at RT shows an intense asymmetric peak at 930.7 $\mathrm{eV}$ (peak A in Figure 1a) with a broad shoulder at $931.9 \mathrm{eV}$ (peak B, Figure 1a) that disappears after the thermal treatment. Moreover, the temperature increase leads to the appearance of a new feature at $934.1 \mathrm{eV}$ (peak C, Figure 1a) that is located at the same energy position as the white line of the $\mathrm{Cu} \mathrm{L}_{3}$-edge spectrum of the $\mathrm{Cu}_{2} \mathrm{O}$ reference sample (Figure 1b). The disappearance of peak $\mathrm{B}$ in the spectrum collected at $160^{\circ} \mathrm{C}$ might be due to the change in coordination of the $\mathrm{Cu}^{2+}$ sites upon temperature treatment, while the appearance of feature $\mathrm{C}$ is consistent with the formation of $\mathrm{Cu}^{+}$species upon reduction of the $\mathrm{Cu}^{2+}$ surface ions. Note that the main transition of the $\mathrm{Cu}_{2} \mathrm{O}$ spectrum has an asymmetric shape with a pronounced tail towards higher energy, while peak $\mathrm{C}$ in 
the spectrum of the thermally treated HKUST-1 is more symmetric. Formally, the $\mathrm{Cu}^{+}$ion has a $d^{10}$ electronic configuration and consequently the $2 p \rightarrow 3 d$ transition resulting in peak $\mathrm{C}$ should not be observed since all the $d$ states are occupied. However, the geometry of the $\mathrm{Cu}^{+}$sites can gives rise to a partial $3 \mathrm{~d}$ character in the empty density of states as in the known case of the linear $\mathrm{Cu}_{2} \mathrm{O}$ oxide. ${ }^{27,28}$ Moreover, both spectra collected at RT and at $160^{\circ} \mathrm{C}$ show an additional broad peak at about $938.4 \mathrm{eV}$ (peaks D, Figure 1a) which is known to be related to the $2 p \rightarrow 4 s$ electronic transition in the $\mathrm{Cu}^{2+}$ ions. ${ }^{27}$

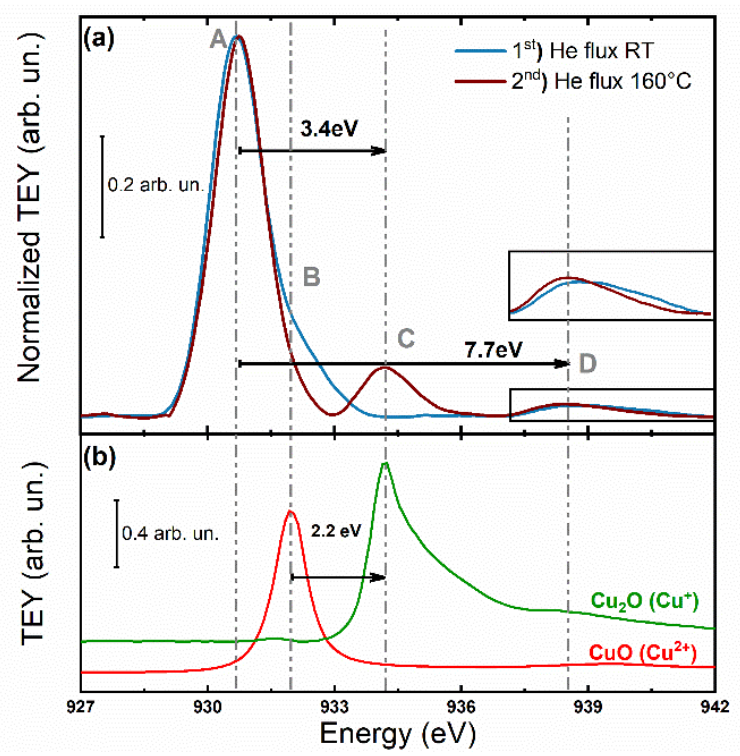

Figure 1. (a) $\mathrm{Cu} \mathrm{L}_{3}$-edge AP-NEXAFS spectra of HKUST-1 collected in 1 bar flux of $\mathrm{He}$ at $\mathrm{RT}$ (blue line) and in $\mathrm{He}$ at $160^{\circ} \mathrm{C}$ (brown line). (b) $\mathrm{Cu} \mathrm{L}_{3}$-edge AP-NEXAFS spectra of $\mathrm{Cu}_{2} \mathrm{O}$ (green line) and $\mathrm{CuO}$ (red line). The spectra in (b) are vertically shifted.

Previous investigations on HKUST-1 have disclosed that temperature annealing leads to the dehydration of the $\mathrm{Cu}^{2+} / \mathrm{Cu}^{2+}$ paddlewheel units present in the pristine MOF and to the formation of $\mathrm{Cu}^{+}$species. The presence of partially reduced $\mathrm{Cu}^{+} / \mathrm{Cu}^{2+}$ dimeric sites has been observed by CO-probed FTIR and XPS ${ }^{29-32,33}$ and a broad discussion has been established in the literature on the origin of the $\mathrm{Cu}^{+}$species in HKUST-1. In particular, two different hypotheses have been made: 
the former suggests that the $\mathrm{Cu}^{+}$ions originate from amorphous $\mathrm{Cu}_{2} \mathrm{O}$ impurities that are formed upon heating at high temperature (e.g. $\left.350^{\circ} \mathrm{C}\right),{ }^{29}$ the latter that $\mathrm{Cu}^{+} / \mathrm{Cu}^{2+}$ dimeric sites originate from the $\mathrm{Cu}^{2+}$ ions in the MOF framework either by reduction of defective clusters or by reduction of $\mathrm{Cu}^{2+}$ cations in perfectly coordinated paddlewheels. ${ }^{32,33}$ Consequently, in our experimental conditions it appears reasonable to hypothesize that the temperature treatment provokes both the dehydration of the pristine $\mathrm{Cu}^{2+} / \mathrm{Cu}^{2+}$ paddlewheel units and the formation of defective $\mathrm{Cu}^{+} / \mathrm{Cu}^{2+}$ sites at the surface of HKUST-1. Note that the soft-XAS spectra collected in TEY detection mode probe only the first few atomic layers from the surface and consequently the effects we are reporting are mainly confined at the surface of our material. The $\mathrm{Cu}^{+}$surface defective sites observed in our AP-NEXAFS spectrum are unlikely due to $\mathrm{Cu}_{2} \mathrm{O}$ impurities since we carried out a mild annealing treatment at $160^{\circ} \mathrm{C}$. In order to support this view, we also measured the $\mathrm{Cu} \mathrm{L}_{2,3-}$ edge spectrum of $\mathrm{CuO}$ in a $\mathrm{He}$ flux increasing the temperature up to $210^{\circ} \mathrm{C}$. In this case no $\mathrm{Cu}^{+}$ ions were formed at the surface as evidenced by the absence of peak $\mathrm{C}$ in the red spectrum of Figure $\mathrm{S} 2$ while only exposure of $\mathrm{CuO}$ to a flux of $\mathrm{CO}$ gas, acting as a reducing agent, led to the reduction of $\mathrm{Cu}^{2+}$ to $\mathrm{Cu}^{+}$(see spectra in brown in Figure $1 \mathrm{~b}$ and S2). Moreover, the PXRD pattern confirms the absence of both $\mathrm{CuO}$ and $\mathrm{Cu}_{2} \mathrm{O}$ impurities in the HKUST-1 at RT (Figure S3). In order to investigate the structure of the defective sites formed upon heating and to provide a conclusive characterization of all of the features present in the HKUST-1 NEXAFS spectra, we performed a theoretical analysis using the FDMNES code. ${ }^{34}$ In the first step, the $\mathrm{Cu}_{2,3}$-edge spectra of the $\mathrm{CuO}$ and $\mathrm{Cu}_{2} \mathrm{O}$ reference samples were calculated in order to benchmark the theoretical framework (see Table S1), and the results are shown in Figure S4. The theoretical spectra are in good agreement with the experimental data shown in Figure $1 \mathrm{~b}$ and both the asymmetric shape of the main absorption edge of the $\mathrm{Cu}_{2} \mathrm{O}$ spectrum, and the more symmetric 
shape of the white line of the $\mathrm{CuO}$ experimental data are properly reproduced by the theoretical calculations (see Figures $1 \mathrm{~b}$ and S4).

In the second step of our analysis the $\mathrm{Cu} \mathrm{L}_{2,3}$-edge spectrum of the pristine MOF at $\mathrm{RT}$ was calculated starting from the crystallographic structure of HKUST- $1 .{ }^{35}$ In this structure the $\mathrm{Cu}^{2+}$ ions are coordinated by five oxygen atoms in a square pyramidal configuration at a $\mathrm{Cu}-\mathrm{O}$ distance of $1.852 \AA$ with the apical oxygen atom belonging to a water molecule placed at $2.207 \AA$ from the $\mathrm{Cu}^{2+}$ ion. The full list of structural parameters used in the theoretical calculations are listed in Table S2. The comparison between the theoretical and experimental $\mathrm{Cu} \mathrm{L}_{3}$-edge spectra of the as synthetized hydrated MOF sample is reported in Figure S5 along with the associated dimeric cluster. The experimental and theoretical curves are in very good agreement as far as the energy position and the relative intensity of peaks $\mathrm{A}$ and $\mathrm{D}$ are concerned, and also peak $\mathrm{B}$, that is mainly associated with the water molecule coordinated in the axial position, is nicely reproduced by the theoretical calculations. In order to uncover the local structural properties of the $\mathrm{Cu}^{2+}$ and $\mathrm{Cu}^{+}$ species present in the thermally treated HKUST-1 sample we carried out a thorough analysis of the NEXAFS data. Firstly, the relative abundance between the $\mathrm{Cu}^{+}$sites formed upon thermal induced defect formation and the square planar (SP)-coordinated $\mathrm{Cu}^{2+}$ sites was estimated by means of a Voigt function fitting as the ratio of the areas of peaks C and A, as shown in Figure S6. Note that these areas need to be normalized by the cross sections of $\mathrm{Cu}^{+}$and $\mathrm{Cu}^{2+}$ and to this aim we have followed the same procedure as described in Fracchia et. al. ${ }^{36}$. This analysis led us to estimate the surface concentration of the $\mathrm{Cu}^{+}$sites to be $22.7 \%$ and, accordingly, that of the $\mathrm{Cu}^{+} / \mathrm{Cu}^{2+}$ dimers to be approximately $45.4 \%$ at the surface $(<10 \mathrm{~nm})$ of our sample.

Next, theoretical $\mathrm{Cu} \mathrm{L}_{3}$-edge spectra were calculated for two distinct models: a $\mathrm{Cu}^{2+} / \mathrm{Cu}^{2+}$ dimer where both metal cations are SP-coordinated, and $\mathrm{a} \mathrm{Cu}^{+} / \mathrm{Cu}^{2+}$ dimer arising from the hypothesized 
oxidative decarboxylation of the former complex where both metal centers are coordinated by three oxygen atoms (Figure 2a). The theoretical $\mathrm{Cu} \mathrm{L}_{3}$-edge spectra belonging to the $\mathrm{Cu}^{2+}$ and $\mathrm{Cu}^{+}$ ions present in the $\mathrm{Cu}^{2+} / \mathrm{Cu}^{2+}$ and $\mathrm{Cu}^{+} / \mathrm{Cu}^{2+}$ clusters and weighted by their estimated surface relative abundance, are shown in Figure 2b, together with the associated molecular structures. The shape of the theoretical spectrum assigned to the $\mathrm{Cu}^{2+}$ cation is fairly symmetric, while that of the $\mathrm{Cu}^{+}$species is skewed towards higher energies similarly to the shape of peak $\mathrm{C}$, and to the experimental and theoretical $\mathrm{Cu} \mathrm{L}_{3}$-edge spectra of $\mathrm{Cu}_{2} \mathrm{O}$. Starting from this result, a theoretical NEXAFS curve has been derived by adding the spectra assigned to the $\mathrm{Cu}^{2+}$ cation in the $\mathrm{Cu}^{2+} / \mathrm{Cu}^{2+}$ dimer together with those of the $\mathrm{Cu}^{+}$and $\mathrm{Cu}^{2+}$ cations in the $\mathrm{Cu}^{+} / \mathrm{Cu}^{2+}$ complex.
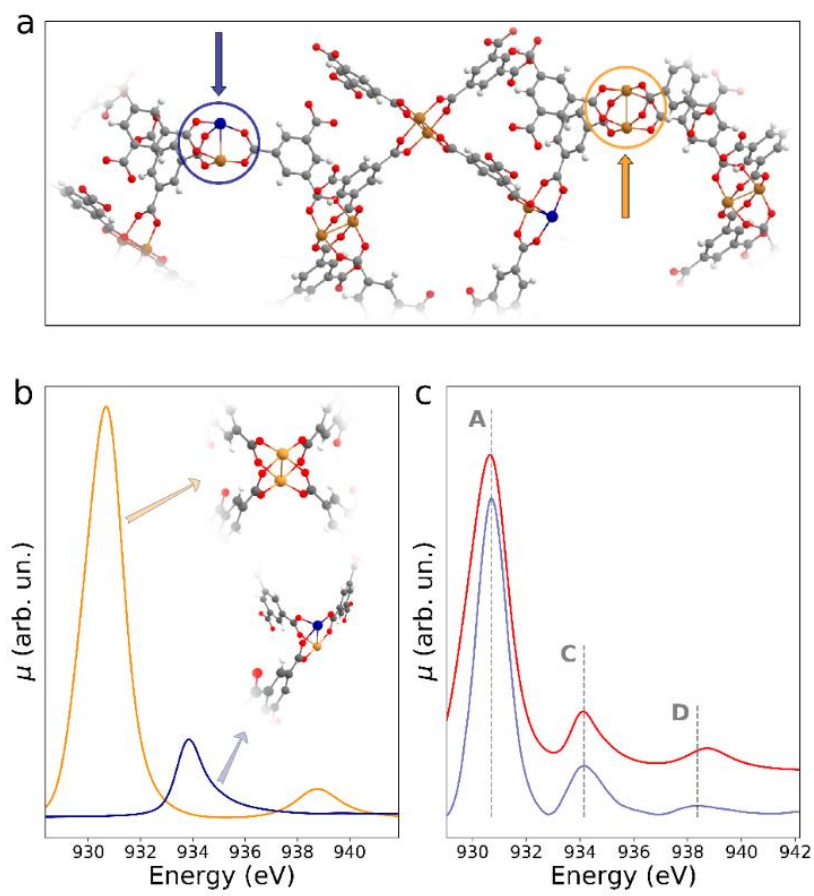

Figure 2. (a) Depiction of the HKUST-1 surface copper sites formed upon treatment of the MOF powder at $160^{\circ} \mathrm{C}$ in He flux. The resulting $\mathrm{Cu}^{2+} / \mathrm{Cu}^{2+}$ and $\mathrm{Cu}^{+} / \mathrm{Cu}^{2+}$ dimeric sites are evidenced by yellow and blue arrows, respectively. (b) Theoretical $\mathrm{Cu} \mathrm{L}_{3}$-edge spectra simulated for the $\mathrm{Cu}^{2+}$ (yellow) and $\mathrm{Cu}^{+}$(blue) cations present in the $\mathrm{Cu}^{2+} / \mathrm{Cu}^{2+}$ and $\mathrm{Cu}^{+} / \mathrm{Cu}^{2+}$ dimers, respectively, and weighted by the estimated relative surface abundance. (c) Comparison between 
the experimental $\mathrm{Cu} \mathrm{L}_{3}$-edge spectrum of HKUST-1 collected at $160^{\circ} \mathrm{C}$ in $\mathrm{He}$ flux (red) and the theoretical spectrum resulting from the weighted sum of the spectra belonging to the $\mathrm{Cu}^{2+}$ and $\mathrm{Cu}^{+}$surface species (light purple).

During this procedure the spectra were weighted by the previously determined relative surface abundance. The resulting total theoretical spectrum (light purple) is compared to the experimental spectrum (red) of the HKUST- 1 collected at $160{ }^{\circ} \mathrm{C}$ in Figure 2c. The agreement between the two spectra is very good and the energy positions and relative intensities of peaks A, C and D are all correctly reproduced, proving the reliability of the analysis.

Overall, these findings confirm that upon a mild annealing at $160^{\circ} \mathrm{C}$ in $\mathrm{He}$ flux the $\mathrm{Cu}^{2+}$ sites present in the pristine HKUST-1 are dehydrated with the formation of SP coordinated clusters, and some of the paddlewheels undergo decarboxylation with the production of partially reduced $\mathrm{Cu}^{+} / \mathrm{Cu}^{2+}$ dimers. The defective sites have been found to be located mostly at the surface as the percentage of reduced copper found in the present study is quite high $(22.7 \%)$, while in the case of the powder MOF, bulk sensitive techniques have estimated the $\mathrm{Cu}^{+}$species formed upon temperature treatment to be about $3 \%$ of the total $\mathrm{Cu}$ in the system. ${ }^{30}$

After elucidating the nature of the regular and defective copper sites in the HKUST-1 we investigated the reactivity of the defective sites in the presence of two prototypical gases namely $\mathrm{CO}_{2}$ and $\mathrm{H}_{2}$ that are generally used to promote the oxidation and reduction of metal cations. To this aim we collected the $\mathrm{Cu} \mathrm{L}_{3}$-edge spectra of the MOF at $160^{\circ}$ fluxing pure $\mathrm{He}$ and its mixtures with $\mathrm{CO}_{2}$ in a reactor cell containing the material. In Figure $3 \mathrm{a}$ we report the $\mathrm{Cu} \mathrm{L}_{3}$-edge experimental spectra of HKUST- 1 collected at $160^{\circ} \mathrm{C}$ in He flux before, during and after exposure to a $2 \%$ flux of $\mathrm{CO}_{2}$. One may observe that upon exposure to $\mathrm{CO}_{2}$ the intensity of peak $\mathrm{C}$ decreases due to the oxidation of $\mathrm{Cu}^{+}$to $\mathrm{Cu}^{2+}$ (Figure 1a) while peak B is not restored. This indicates that almost all of the thermally induced $\mathrm{Cu}^{+} / \mathrm{Cu}^{2+}$ defective sites are oxidized by $\mathrm{CO}_{2}$, while no water 
molecules coordinate the $\mathrm{Cu}^{2+}$ ions in the apical positions. This further confirms that peak $\mathrm{B}$ in the RT spectrum of the HKUST-1 is the fingerprint of the water ligands and to get a definite proof the theoretical spectrum calculated for the $\mathrm{Cu}^{2+}$ cation in the dehydrated $\mathrm{Cu}^{2+} / \mathrm{Cu}^{2+}$ dimeric complex has been compared to the experimental spectrum obtained after the $\mathrm{CO}_{2}$ flux in Figure $\mathrm{S} 8$.
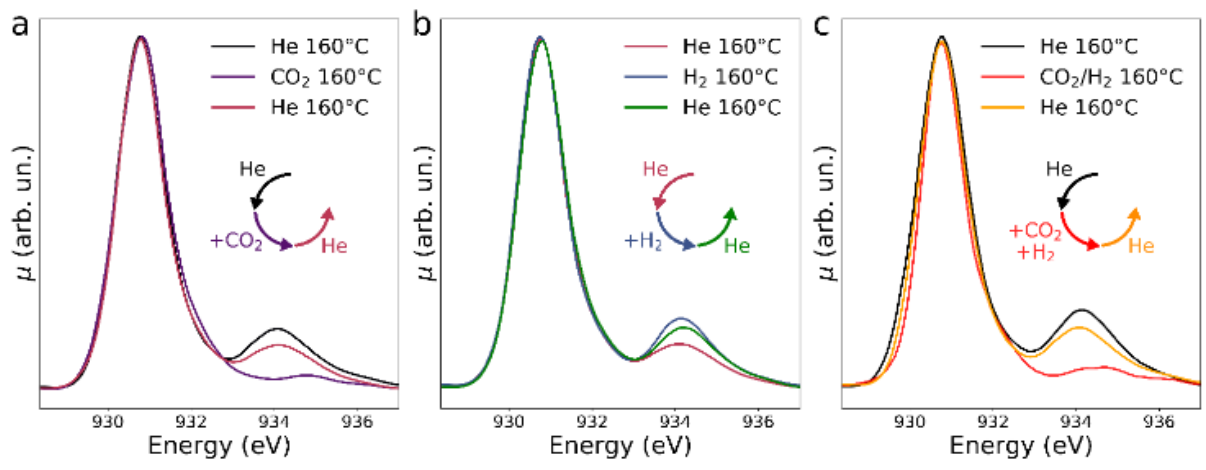

Figure 3. Series of $\mathrm{Cu} \mathrm{L}_{3}$-edge AP-NEXAFS spectra of HKUST-1: (a) collected at $160^{\circ} \mathrm{C}$ in 1 bar of He flux before (black line) and after exposure to $\mathrm{CO}_{2}$ (violet line), and in 1 bar of He flux after removal of $\mathrm{CO}_{2}$ (dark red line). (b) in 1 bar He flux before (dark red line) and after exposure to $\mathrm{H}_{2}$ (blue line), and in 1 bar of $\mathrm{He}$ flux after removal of $\mathrm{H}_{2}$ (green line). (c) at $160^{\circ} \mathrm{C}$ in a 1 bar flux of He before (black line), during (red line) and after exposure to a flux of a gaseous mixture containing $\mathrm{CO}_{2}(2 \%)$ and $\mathrm{H}_{2}(6 \%)$ (orange line). In order to aid the visualization, in each panel the chronological order with which the spectra were measured is portrayed using sets of arrows arranged in circles whose colors match those of the corresponding presented spectra and whose orientations evidence the temporal sequence with which each spectrum was collected.

The agreement between the experimental and theoretical spectra is very good and the shape and width of peak A is nicely reproduced.

Looking at Figure 3a one may note that when the $\mathrm{CO}_{2}$ flux is interrupted the intensity of peak $\mathrm{C}$ is almost completely recovered, showing that the defective $\mathrm{Cu}^{+} / \mathrm{Cu}^{2+}$ sites on the MOF surface are almost completely restored. This finding demonstrates that the oxidation of the $\mathrm{Cu}^{+}$sites in the presence of $\mathrm{CO}_{2}$ is a reversible process. Finally, the sample previously exposed to $\mathrm{CO}_{2}$ has been 
fluxed with $\mathrm{He}$ containing $6 \%$ of $\mathrm{H}_{2}$ and the percentage of $\mathrm{Cu}^{+} / \mathrm{Cu}^{2+}$ defective sites further increases, as demonstrated by the intensity of peak C (see Figure 3b).

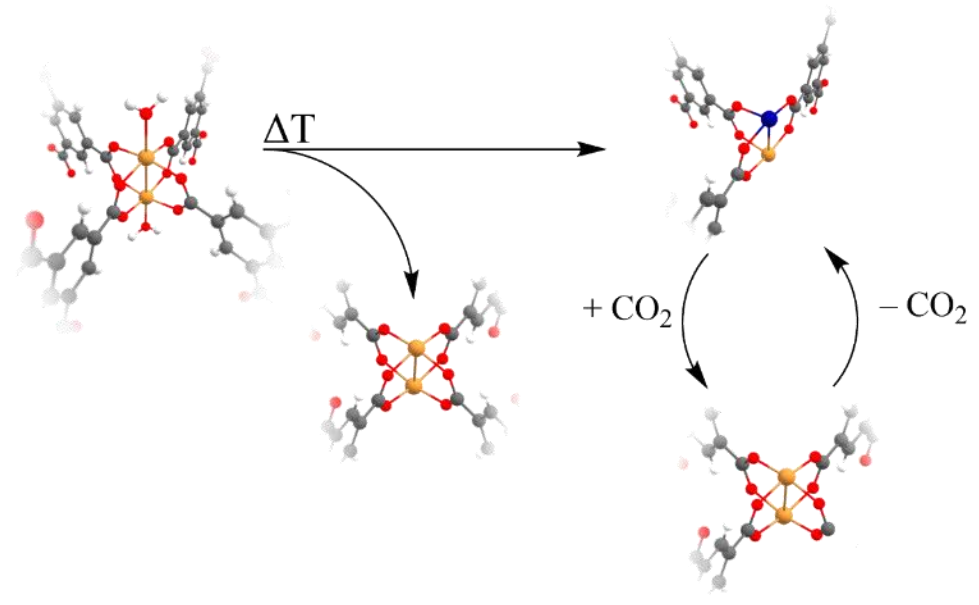

Figure 4. Proposed mechanistic scheme for the investigated surface properties of HKUST-1. The paddlewheel unit of the pristine MOF is converted to the dehydrated $\mathrm{Cu}^{2+} / \mathrm{Cu}^{2+}$ dimer upon temperature treatment at $160{ }^{\circ} \mathrm{C}$, which in turn undergoes a partial decarboxylation to yield a $\mathrm{Cu}^{+} / \mathrm{Cu}^{2+}$ complex. The surface $\mathrm{Cu}^{2+} / \mathrm{Cu}^{2+}$ dimer is reversibly replenished upon exposure of the $\mathrm{Cu}^{+}$sites to $\mathrm{CO}_{2}$ in the gas phase.

In order to shed light into the mechanism of the $\mathrm{CO}_{2}$ interaction with the MOF, the O K-edge APNEXAFS spectra of HKUST- 1 at $160^{\circ} \mathrm{C}$ before and during the $\mathrm{CO}_{2}$ flux have been collected (Figure S7). By looking at the $\mathrm{O}$ K-edge spectra of the $\mathrm{CO}$ and $\mathrm{CO}_{2}$ gases reported in Figure $\mathrm{S} 7$ for comparison, the decomposition of $\mathrm{CO}_{2}$ to $\mathrm{CO}$ during the flux on the MOF can be excluded as the main peaks of the $\pi$ bonds of the $\mathrm{CO}_{2}$ gas are clearly present and of the $\mathrm{CO}$ gas, that falls at separate energy, is absent in the $\mathrm{O}$ K-edge AP-NEXAFS spectrum of HKUST-1 under $\mathrm{CO}_{2}$ flux. All together these findings suggest that the mechanism of $\mathrm{CO}_{2}$ interaction is through a redox-active transition on the metal $\mathrm{Cu}^{+}$defective sites. Figure 4 shows the mechanistic picture we have derived from the temperature induced surface properties of HKUST-1. In particular, it can be hypothesized that the presence of defective sites in the pristine HKUST-1 enables the partial reduction of the 
dehydrated $\mathrm{Cu}^{2+} / \mathrm{Cu}^{2+}$ units to $\mathrm{Cu}^{+} / \mathrm{Cu}^{2+}$ dimers upon a temperature treatment at $160{ }^{\circ} \mathrm{C}$, and that the $\mathrm{Cu}^{2+} / \mathrm{Cu}^{2+}$ and $\mathrm{Cu}^{+} / \mathrm{Cu}^{2+}$ surface complexes reversibly shuttle between each other in the presence or absence of a $\mathrm{CO}_{2}$ external gas flux.

Finally, in order to investigate the selectivity of the $\mathrm{Cu}^{+}$defective sites in HKUST-1 towards $\mathrm{CO}_{2}$ capture, we have monitored the evolution of the $\mathrm{Cu} \mathrm{L}_{3}$-edge spectrum of the $\mathrm{MOF}$ at $160^{\circ} \mathrm{C}$ under a flux of $\mathrm{He}$ containing a mixture of $\mathrm{CO}_{2}(2 \%)$ and $\mathrm{H}_{2}(6 \%)$. The results are reported in Figure $3 \mathrm{c}$, where it appears that the intensity of peak $\mathrm{C}$ is greatly reduced upon flux of gaseous mixture showing that the $\mathrm{Cu}^{+}$sites of the material preferentially interact with $\mathrm{CO}_{2}$ undergoing an oxidation process. It is of note that the presence of $\mathrm{H}_{2}$ in the flux does not significantly affect such interaction, since the $\mathrm{Cu} \mathrm{L}_{3}$-edge spectra of the sample measured at $160^{\circ} \mathrm{C}$ under a $\mathrm{He}$ flux containing $\mathrm{CO}_{2}$ $(2 \%) / \mathrm{H}_{2}(6 \%)$ (Figure $3 \mathrm{c}$, red line) and the one containing only $\mathrm{CO}_{2}(2 \%)$ are very similar (Figure $3 a$, violet line), confirming that the $\mathrm{Cu}^{+}$sites interact easily and preferentially with $\mathrm{CO}_{2}$. The $\mathrm{CO}_{2}$ capture of the MOF is again proven to be reversible since once the $\mathrm{CO}_{2}$ gas flux is interrupted peak $\mathrm{C}$ is almost completely recovered (Figure $3 \mathrm{c}$, orange line).

In conclusion a thorough characterization of the thermally induced properties of the surface $\mathrm{Cu}$ sites in the HKUST-1 has been achieved by combining an innovative experimental technique such as AP-NEXAFS with theoretical support. For the first time the $\mathrm{Cu} \mathrm{L}_{3}$-edge spectra of the HKUST1 have been collected at ambient pressure ( 1 bar) in a temperature range going from $\mathrm{RT}$ to $160^{\circ} \mathrm{C}$ in different gas environment $\left(\mathrm{He}, \mathrm{CO}_{2}, \mathrm{H}_{2}\right.$ and $\left.\mathrm{CO}_{2} / \mathrm{H}_{2}\right)$. The AP-NEXAFS spectroscopy allowed us to fully unveil the structural properties of the copper sites present in the first layers of HKUST1 and the unique surface sensitivity of this technique enabled us to prove that defective $\mathrm{Cu}^{+} / \mathrm{Cu}^{2+}$ dimeric sites are largely present at the surface of the investigated material. Within our experimental and theoretical framework, we have clear evidence of the formation of $\mathrm{Cu}^{+}$surface sites upon 
temperature treatment of the pristine MOF at $160^{\circ} \mathrm{C}$, and we estimate the $\mathrm{Cu}^{+} / \mathrm{Cu}^{2+}$ species to be ca. $45.4 \%$ of the total amount of $\mathrm{Cu}$-dimers at the surface of the sample. Moreover, we propose that the $\mathrm{Cu}^{+} / \mathrm{Cu}^{2+}$ dimeric units arise from a decarboxylation of dehydrated $\mathrm{Cu}^{2+} / \mathrm{Cu}^{2+}$ paddlewheel units while the formation of $\mathrm{Cu}^{+}$defective sites is unlikely due to the presence of $\mathrm{Cu}_{2} \mathrm{O}$ impurities in the MOF, as previously suggested, ${ }^{23}$ since the very strong $\mathrm{Cu}-\mathrm{O}$ bonds contained in the oxide should not be affected by an annealing at $160^{\circ} \mathrm{C}$. Further, we show for the first time that $\mathrm{CO}_{2}$ may be fruitfully employed as a probe molecule in the gas phase to study the surface properties of HKUST-1 and reversibly oxidize the temperature induced $\mathrm{Cu}^{+}$sites. We believe that our results may lead to an increased understanding of the surface properties of HKUST-1 and pave the way for their rational use in processes of interest for catalysis.

\section{ASSOCIATED CONTENT}

In the Supporting Information file a detailed information about a quick summary in literature about the defects in HKUST-1, experimental and theoretical soft-XAS, PXRD pattern, defects quantifications are provided. The following files are available free of charge.

AUTHOR INFORMATION 


\section{Notes}

The authors declare no competing financial interests.

\section{ACKNOWLEDGMENT}

The project is founded by the Nanoscience Foundry and Fine Analysis (NFFA-MIUR Italy Progetti Internazionali) project. The Italian Ministry of University and Research is acknowledged for financial support through the PRIN 2107 program (project 2017KKP5ZR). VC thanks the Università degli Studi di Milano for partial funding (PSR2020 - Linea A). The Prof. Paolo Ghigna is acknowledged for the fruitful discussion.

\section{REFERENCES}

(1) Furukawa, H.; Cordova, K. E.; O’Keeffe, M.; Yaghi, O. The Chemistry and Applications of Metal-Organic Frameworks. Science 2013, 341 (6149). https://doi.org/10.1126/SCIENCE.1230444.

(2) Yaghi, O. M.; Kalmutzki, M. J.; Diercks, C. S. Introduction to Reticular Chemistry: MetalOrganic Frameworks and Covalent Organic Frameworks. Introd. to Reticular Chem. Met. Fram. Covalent Org. Fram. 2019, 1-509. https://doi.org/10.1002/9783527821099.

(3) Kökçam-Demir, Ü.; Goldman, A.; Esrafili, L.; Gharib, M.; Morsali, A.; Weingart, O.; Janiak, C. Coordinatively Unsaturated Metal Sites (Open Metal Sites) in Metal-Organic Frameworks: Design and Applications. Chem. Soc. Rev. 2020, 49 (9), 2751-2798. https://doi.org/10.1039/C9CS00609E.

(4) Ravi, M.; Ranocchiari, M.; van Bokhoven, J. A. The Direct Catalytic Oxidation of Methane to Methanol-A Critical Assessment. Angew. Chemie Int. Ed. 2017, 56 (52), 16464-16483. https://doi.org/10.1002/anie.201702550. 
(5) Li, J.-R.; Kuppler, R. J.; Zhou, H.-C. Selective Gas Adsorption and Separation in MetalOrganic Frameworks. Chem. Soc. Rev. 2009, 38 (5), 1477-1504. https://doi.org/10.1039/B802426J.

(6) Nijem, N.; Bluhm, H.; Ng, M. L.; Kunz, M.; Leone, S. R.; Gilles, M. K. $\mathrm{Cu}^{1+}$ in HKUST1: Selective Gas Adsorption in the Presence of Water. Chem. Commun. 2014, 50 (70), 10144-10147. https://doi.org/10.1039/c4cc02327g.

(7) Teo, H. W. B.; Chakraborty, A.; Kayal, S. Evaluation of $\mathrm{CH}_{4}$ and $\mathrm{CO}_{2}$ Adsorption on HKUST-1 and MIL-101(Cr) MOFs Employing Monte Carlo Simulation and Comparison with Experimental Data. Appl. Therm. Eng. 2017, 110, 891-900. https://doi.org/10.1016/j.applthermaleng.2016.08.126.

(8) J. Murray, L.; Mircea Dincă; R. Long, J. Hydrogen Storage in Metal-Organic Frameworks. Chem. Soc. Rev. 2009, 38 (5), 1294-1314. https://doi.org/10.1039/B802256A.

(9) Nam, D. H.; Bushuyev, O. S.; Li, J.; De Luna, P.; Seifitokaldani, A.; Dinh, C. T.; García De Arquer, F. P.; Wang, Y.; Liang, Z.; Proppe, A. H.; et al. Metal-Organic Frameworks Mediate $\mathrm{Cu}$ Coordination for Selective $\mathrm{CO}_{2}$ Electroreduction. J. Am. Chem. Soc. 2018, 140 (36), 11378-11386. https://doi.org/10.1021/jacs.8b06407.

(10) Lee, J.; Farha, O. K.; Roberts, J.; Scheidt, K. A.; Nguyen, S. T.; Hupp, J. T. Metal-Organic Framework Materials as Catalysts. Chem. Soc. Rev. 2009, 38 (5), 1450-1459. https://doi.org/10.1039/b807080f.

(11) Wang, Q.; Gao, Q.; Al-Enizi, A. M.; Nafady, A.; Ma, S. Recent Advances in MOF-Based Photocatalysis: Environmental Remediation under Visible Light. Inorg. Chem. Front. 2020, 
7 (2), 300-339. https://doi.org/10.1039/C9QI01120J.

(12) Shustova, N. B.; Cozzolino, A. F.; Reineke, S.; Baldo, M.; Dincă, M. Selective Turn-On Ammonia Sensing Enabled by High-Temperature Fluorescence in Metal-Organic Frameworks with Open Metal Sites. J. Am. Chem. Soc. 2013, 135 (36), 13326-13329. https://doi.org/10.1021/JA407778A.

(13) Chaemchuen, S.; Xiao, X.; Klomkliang, N.; Yusubov, M. S.; Verpoort, F. Tunable MetalOrganic Frameworks for Heat Transformation Applications. Nanomaterials 2018, 8 (9). https://doi.org/10.3390/NANO8090661.

(14) Wu, Y. N.; Zhou, M.; Li, S.; Li, Z.; Li, J.; Wu, B.; Li, G.; Li, F.; Guan, X. Magnetic MetalOrganic Frameworks: $\gamma-\mathrm{Fe}_{2} \mathrm{O}_{3} @$ MOFs via Confined in Situ Pyrolysis Method for Drug Delivery. Small 2014, 10 (14), 2927-2936. https://doi.org/10.1002/smll.201400362.

(15) Sun, Y.; Zheng, L.; Yang, Y.; Qian, X.; Fu, T.; Li, X.; Yang, Z.; Yan, H.; Cui, C.; Tan, W. Metal-Organic Framework Nanocarriers for Drug Delivery in Biomedical Applications. Nano-Micro Lett. 2020, 12 (1), 1-29. https://doi.org/10.1007/S40820-020-00423-3.

(16) Sumida, K.; Rogow, D. L.; Mason, J. A.; McDonald, T. M.; Bloch, E. D.; Herm, Z. R.; Bae, T. H.; Long, J. R. Carbon Dioxide Capture in Metal-Organic Frameworks. Chem. Rev. 2012, 112 (2), 724-781. https://doi.org/10.1021/cr2003272.

(17) Trickett, C. A.; Helal, A.; Al-Maythalony, B. A.; Yamani, Z. H.; Cordova, K. E.; Yaghi, O. M. The Chemistry of Metal-Organic Frameworks for $\mathrm{CO}_{2}$ Capture, Regeneration and $\begin{array}{lllllll}\text { Conversion. } & \text { Nat. } & \text { Rev. } & \text { Mater. } & \text { 2017, } & 2 & \text { (8), }\end{array}$ https://doi.org/10.1038/natrevmats.2017.45. 
(18) Bui, M.; Adjiman, C. S.; Bardow, A.; Anthony, E. J.; Boston, A.; Brown, S.; Fennell, P. S.; Fuss, S.; Galindo, A.; Hackett, L. A.; et al. Carbon Capture and Storage (CCS): The Way Forward. Energy Environ. Sci. 2018, $11 \quad$ (5), 1062-1176. https://doi.org/10.1039/C7EE02342A.

(19) McDonald, T. M.; Lee, W. R.; Mason, J. A.; Wiers, B. M.; Hong, C. S.; Long, J. R. Capture of Carbon Dioxide from Air and Flue Gas in the Alkylamine-Appended Metal-Organic Framework Mmen- $\mathrm{Mg}_{2}$ (Dobpdc). J. Am. Chem. Soc. 2012, 134 (16), 7056-7065. https://doi.org/10.1021/JA300034J.

(20) Siegelman, R. L.; McDonald, T. M.; Gonzalez, M. I.; Martell, J. D.; Milner, P. J.; Mason, J. A.; Berger, A. H.; Bhown, A. S.; Long, J. R. Controlling Cooperative $\mathrm{CO}_{2}$ Adsorption in Diamine-Appended $\mathrm{Mg}_{2}$ (Dobpdc) Metal-Organic Frameworks. J. Am. Chem. Soc. 2017, 139 (30), 10526-10538. https://doi.org/10.1021/JACS.7B05858.

(21) Kim, E. J.; Siegelman, R. L.; Jiang, H. Z. H.; Forse, A. C.; Lee, J.-H.; Martell, J. D.; Milner, P. J.; Falkowski, J. M.; Neaton, J. B.; Reimer, J. A.; et al. Cooperative Carbon Capture and Steam Regeneration with Tetraamine-Appended Metal-Organic Frameworks. Science. 2020, 369 (6502), 392-396. https://doi.org/10.1126/SCIENCE.ABB3976.

(22) Chui, S. S. A Chemically Functionalizable Nanoporous Material $\left[\mathrm{Cu}_{3}(\mathrm{TMA})_{2}\left(\mathrm{H}_{2} \mathrm{O}\right)_{3}\right] \mathrm{N}$. Science. 1999, 283 (5405), 1148-1150. https://doi.org/10.1126/science.283.5405.1148.

(23) Prestipino, C.; Regli, L.; Vitillo, J. G.; Bonino, F.; Damin, A.; Lamberti, C.; Zecchina, A.; Solari, P. L.; Kongshaug, K. O.; Bordiga, S. Local Structure of Framework Cu(II) in HKUST-1 Metallorganic Framework: Spectroscopic Characterization upon Activation and 
Interaction with Adsorbates. Chem. Mater. 2006, 18 (5), 1337-1346. https://doi.org/10.1021/cm052191g.

(24) Borfecchia, E.; Maurelli, S.; Gianolio, D.; Groppo, E.; Chiesa, M.; Bonino, F.; Lamberti, C. Insights into Adsorption of NH 3 on HKUST-1 Metal-Organic Framework: A Multitechnique Approach. J. Phys. Chem. C 2012, 116 (37), 19839-19850. https://doi.org/10.1021/jp305756k.

(25) Todaro, M.; Buscarino, G.; Sciortino, L.; Alessi, A.; Messina, F.; Taddei, M.; Ranocchiari, M.; Cannas, M.; Gelardi, F. M. Decomposition Process of Carboxylate MOF HKUST-1 Unveiled at the Atomic Scale Level. J. Phys. Chem. C 2016, 120 (23), 12879-12889. https://doi.org/10.1021/acs.jpcc.6b03237.

(26) Huang, C.; Dong, J.; Sun, W.; Xue, Z.; Ma, J.; Zheng, L.; Liu, C.; Li, X.; Zhou, K.; Qiao, X.; et al. Coordination Mode Engineering in Stacked-Nanosheet Metal-Organic Frameworks to Enhance Catalytic Reactivity and Structural Robustness. Nat. Commun. 2019101 2019, 10 (1), 1-10. https://doi.org/10.1038/s41467-019-10547-9.

(27) Grioni, M.; Goedkoop, J. B.; Schoorl, R.; de Groot, F. M. F.; Fuggle, J. C.; Schäfers, F.; Koch, E. E.; Rossi, G.; Esteva, J.-M.; Karnatak, R. C. Studies of Copper Valence States with $\mathrm{Cu} \mathrm{L}_{3}$ X-Ray-Absorption Spectroscopy. Phys. Rev. B 1989, 39 (3), 1541-1545. https://doi.org/10.1103/PhysRevB.39.1541.

(28) Wang, Y.; Lany, S.; Ghanbaja, J.; Fagot-Revurat, Y.; Chen, Y. P.; Soldera, F.; Horwat, D.; Mücklich, F.; Pierson, J. F. Electronic Structures of $\mathrm{Cu}_{2} \mathrm{O}, \mathrm{Cu}_{4} \mathrm{O}_{3}$, and $\mathrm{CuO}$ : A Joint Experimental and Theoretical Study. Phys. Rev. B 2016, 94 (24), 1-10. 
https://doi.org/10.1103/PhysRevB.94.245418.

(29) Bordiga, S.; Regli, L.; Bonino, F.; Groppo, E.; Lamberti, C.; Xiao, B.; Wheatley, P. S.; Morris, R. E.; Zecchina, A. Adsorption Properties of HKUST-1 toward Hydrogen and Other Small Molecules Monitored by IR. Phys. Chem. Chem. Phys. 2007, 9 (21), 2676-2685. https://doi.org/10.1039/b703643d.

(30) Szanyi, J.; Daturi, M.; Clet, G.; Baer, D. R.; Peden, C. H. F. Well-Studied Cu-BTC Still Serves Surprises: Evidence for Facile $\mathrm{Cu}^{2+} \mathrm{Cu}^{+}$Interchange. Phys. Chem. Chem. Phys. 2012, 14 (13), 4383-4390. https://doi.org/10.1039/c2cp23708c.

(31) Wang, J.; Wang, W.; Fan, Z.; Chen, S.; Nefedov, A.; Heißler, S.; Fischer, R. A.; Wöll, C.; Wang, Y. Defect-Engineered Metal-Organic Frameworks: A Thorough Characterization of Active Sites Using CO as a Probe Molecule. J. Phys. Chem. C 2020, 125 (1), 593-601. https://doi.org/10.1021/ACS.JPCC.0C09738.

(32) Wang, W.; Sharapa, D. I.; Chandresh, A.; Nefedov, A.; Heißler, S.; Heinke, L.; Studt, F.; Wang, Y.; Wöll, C. Interplay of Electronic and Steric Effects to Yield Low-Temperature CO Oxidation at Metal Single Sites in Defect-Engineered HKUST-1. Angew. Chemie Int. Ed. 2020, 59 (26), 10514-10518. https://doi.org/10.1002/ANIE.202000385.

(33) St. Petkov, P.; Vayssilov, G. N.; Liu, J.; Shekhah, O.; Wang, Y.; Wöll, C.; Heine, T. Defects in MOFs: A Thorough Characterization. ChemPhysChem 2012, 13 (8), 2025-2029. https://doi.org/10.1002/cphc.201200222.

(34) Bunău, O.; Joly, Y. Self-Consistent Aspects of X-Ray Absorption Calculations. J. Phys. Condens. Matter 2009, 21 (34), 11. https://doi.org/10.1088/0953-8984/21/34/345501. 
(35) Yakovenko, A. A.; Reibenspies, J. H.; Bhuvanesh, N.; Zhou, H.-C. Generation and Applications of Structure Envelopes for Porous Metal-Organic Frameworks. J. Appl. Crystallogr. 2013, 46 (2), 346-353. https://doi.org/10.1107/S0021889812050935.

(36) Fracchia, M.; Ghigna, P.; Pozzi, T.; Anselmi Tamburini, U.; Colombo, V.; Braglia, L.; Torelli, P. Stabilization by Configurational Entropy of the $\mathrm{Cu}(\mathrm{II})$ Active Site during $\mathrm{CO}$ Oxidation on $\mathrm{Mg} 0.2 \mathrm{Co} 0.2 \mathrm{Ni0} .2 \mathrm{Cu} 0.2 \mathrm{Zn} 0.2 \mathrm{O}$. J. Phys. Chem. Lett. 2020, 11 (9), 35893593. https://doi.org/10.1021/acs.jpclett.0c00602. 